\title{
The use of angiotensin-converting enzyme inhibitors in the treatment of heart failure in hospital practice
}

\author{
Constantinos G Missouris, Graham A MacGregor
}

\begin{abstract}
Summary
Several well-controlled trials in patients with heart failure have shown that the use of angiotensin-converting enzyme (ACE) inhibitors, in combination with a diuretic, causes a reduction in mortality and morbidity, which seems to be mainly due to a reduction in fatal and nonfatal cardiovascular events. Our aim was to determine whether 249 consecutive patients discharged from hospital with a primary diagnosis of heart failure were routinely being treated with an ACE inhibitor at an appropriate dose. At the time of admission to hospital, $91(36.5 \%)$ were receiving a combination of a diuretic and an ACE inhibitor, $129(51.8 \%)$ were receiving a diuretic alone, and $29(11.6 \%)$ had not previously received either a diuretic or an ACE inhibitor. At the time of discharge from hospital all patients were on a diuretic and $144(57.8 \%)$ were also receiving an ACE inhibitor. Although 41 patients $(16.5 \%)$ had a relative or absolute contraindication for the use of an ACE inhibitor, 64 patients $(25.7 \%)$ with no contraindication were not receiving an ACE inhibitor. Many of the patients who were prescribed an ACE inhibitor were given it at an inappropriate dose; only 24 patients $(16.7 \%)$ were on the dose that was used in the clinical trials showing a reduction in mortality. These results show that in one in four patients admitted to hospital with heart failure who should be receiving an ACE inhibitor by the time of discharge, are not. The average age of these patients was 76 years. Whilst it has been shown that the benefit of ACE inhibitors does not appear to be agerelated, most published studies have not included many patients over the age of 80 . Specific studies looking at the effect of ACE inhibitors in elderly patients would be helpful, as well as studies to determine the optimum treatment regimen for this age group.
\end{abstract}

Keywords: heart failure, ACE inhibitors

Congestive heart failure is a syndrome characterised by changes in left ventricular systolic and /or diastolic function which can ultimately result in reduced exercise tolerance, impaired quality of life, and a five-year mortality in excess of $50 \% .^{1}$ Heart failure imposes a heavy financial burden on any healthcare system due to the large number of hospital admissions. ${ }^{2,3}$ Recently, a series of randomised, double-blind controlled trials have consistently shown that, in patients already on a diuretic, the addition of an angiotensin-converting enzyme (ACE) inhibitor significantly improves symptoms and signs of chronic heart failure and increases survival. ${ }^{4,5}$ In addition, ACE inhibitors have been shown to slow or reverse left ventricular dilatation in patients with asymptomatic left ventricular dysfunction ${ }^{6,7}$ and attenuate left ventricular dilatation and progression to symptomatic heart failure in patients following myocardial infarction. ${ }^{8-10}$

In a small pilot study in our hospital we found that some patients discharged from our institution with the diagnosis of heart failure were not receiving an ACE inhibitor. We therefore reviewed the notes of in-patients admitted to our hospital with heart failure to see how many were receiving ACE inhibitors and whether those who were not had any specific contraindication.

\section{Patients and methods}

We performed a retrospective analysis of all case notes of patients admitted to St George's Hospital during the period January to October 1994 with the primary diagnosis of heart failure. The diagnosis of heart failure was made by the admitting team based on clinical symptoms and signs and evidence of pulmonary oedema and/or cardiomegaly on a chest Xray. In some patients the diagnosis of heart failure was supported by echocardiography. A list of all admissions was provided by the clinical coding department; 257 notes were requested, of which 249 were available. The results are expressed as means plus or minus standard deviations.

\section{Results}

A total of 249 subjects were included in the study (128 males; mean age $76 \pm 11$ years). Two hundred and seven were white, 23 black and 19 Asian. One hundred and sixty were drawn from general medical firms, and the rest from the departments of geriatrics (66) and cardiology (23). The aetiology of heart failure, as stated in the notes, is shown in box 1. The 


\begin{tabular}{|lr|}
\hline \multicolumn{2}{|l|}{ Aetiology of heart failure $(\boldsymbol{n}=\mathbf{2 4 9})$} \\
\hline Aetiology & $n$ \\
- ischaemic heart disease & 135 \\
- acute myocardial infarction & 27 \\
- aortic and/or mitral valve disease & 18 \\
- dilated cardiomyopathy & 8 \\
- fast atrial fibrillation & 16 \\
- hypertensive heart failure & 3 \\
- unspecified & 42 \\
\hline
\end{tabular}

Box 1

diagnosis was confirmed in 146 patients $(58.6 \%)$ using transthoracic echocardiography. Furthermore, 60 patients were on treatment for hypertension, 42 were diabetics (six on insulin), 21 had a cerebrovascular event, 13 had symptomatic peripheral vascular disease and 10 had renal impairment (plasma creatinine $>500 \mu \mathrm{mol} / 1)$.

At the time of admission to hospital of the 249 patients with heart failure, 91 patients $(36.5 \%)$ were on a combination of a diuretic and an ACE inhibitor, 129 patients $(51.8 \%)$ were receiving a diuretic alone and 29 (11.6\%) had not previously received either a diuretic or an ACE inhibitor. At the time of discharge from hospital all patients were on a diuretic, $144(57.8 \%)$ were also receiving an ACE inhibitor $(67>75$ years and $34>80$ years of age). Forty-one patients $(16.5 \%)$ had a relative or absolute contraindication for the use of an ACE inhibitor (box 2), but 64 (25.7\%) patients with no contraindications to ACE inhibitors were not receiving them (51>75 years and $37>80$ years of age).

In those patients receiving an ACE inhibitor, 92 patients were receiving treatment with captopril (mean daily dose $42 \mathrm{mg} \pm 25 \mathrm{mg}$ ); six were prescribed it once a day, 53 twice a day and 33 three times a day. Forty-eight patients were treated with enalapril (mean daily dose $17 \mathrm{mg} \pm 15 \mathrm{mg}$ ); 26 were prescribed it once a day, 21 twice a day and one three times a day. Four patients were on lisinopril (mean daily dose $14 \mathrm{mg} \pm 8 \mathrm{mg}$ ); all were on it once a day. Only 24 patients $(16.7 \%)$ were on the dose that was used in the clinical trials where ACE inhibitors showed a reduction in mortality. Two patients were commenced on an ACE inhibitor and three had the dose increased during the three-month follow-up. Twentyseven patients died during hospital admission and 22 during the three-month follow-up (40 over the age of 75 years).

\begin{tabular}{|c|c|}
\hline $\begin{array}{l}\text { Patients with a contraindication } \\
\text { treatment with an } \mathrm{ACE} \text { inhibito }\end{array}$ & \\
\hline $\begin{array}{l}\text { Contraindication } \\
\text { - hypotension and deterioration in renal } \\
\text { function } \\
\text { - severe aortic valve stenosis } \\
\text { - bilateral renal artery stenosis or stenosis } \\
\text { to a single functioning kidney } \\
\text { - suspected renal artery stenosis } \\
\text { - severe cough }\end{array}$ & $\begin{array}{r}n \\
23 \\
9 \\
5 \\
\\
2 \\
2\end{array}$ \\
\hline
\end{tabular}

Box 2
Seventy-six patients were receiving antiarrhythmic treatment on discharge for atrial fibrillation (digoxin 61, amiodarone 5). Of these, $30(39.8 \%)$ were taking anticoagulation to prevent embolic events. The notes in nine patients showed a contraindication for anticoagulation: gastrointestinal blood loss (4), malignancy (3) and other (2). The remaining 37 patients had no recorded contraindication but the majority were elderly (36>75 years and $21>80$ years of age). All these patients were treated with aspirin instead.

\section{Discussion}

Our results clearly show that, on discharge from hospital, approximately one in four patients with heart failure and without a documented contraindication, are not prescribed an ACE inhibitor. This state of affairs is unlikely to be unique to this hospital. This is surprising in view of the overwhelming evidence that ACE inhibitors reduce fatal and nonfatal events in patients with overt heart failure, ${ }^{4,5}$ and slow or reverse left ventricular dilatation in patients with asymptomatic left ventricular systolic dysfunction ${ }^{7}$ or following myocardial infarction. $9,11,12$

The prevalence of heart failure continues to increase, ${ }^{13,14}$ in spite of better treatment of hypertension and other risk factors for coronary heart disease. ACE inhibitors have been shown to reduce or reverse the extent of ventricular dilatation and the incidence of reinfarction. Little is known, however, of the optimum dose of ACE inhibitor required to observe the expected improvement in cardiovascular events. Continuous inhibition of the angiotensin-converting enzyme is probably desirable. However, many of the patients who were prescribed an ACE inhibitor were given it at an inappropriate dose; only $16.7 \%$ of patients were on the doses used in the clinical trials showing a reduction in morbidity and mortality: CONSENSUS ${ }^{4}(10-20 \mathrm{mg}$ enalapril twice a day); $\operatorname{SOLVD}^{5}$ (10 mg enalapril twice a day), SAVE $^{9}$ (captopril $50 \mathrm{mg}$ three times a day), and AIRE $^{6}$ ( $5 \mathrm{mg}$ ramipril twice a day). Similar results were also reported in 157 patients seen in tertiary referral clinics for heart failure. ${ }^{13}$ Even though no information is provided on the way the patients were selected, a wide range of different ACE inhibitor regimes was used, and only $46 \%$ of patients were receiving doses suggested by the results of survival trials.

The incidence of heart failure increases exponentially with age. It affects about $1 \%$ of people in their 50 s and rises to $10 \%$ of those in their $80 \mathrm{~s} .{ }^{16,17}$ Therefore, to have an impact on the overall mortality and morbidity from heart failure one should aim to treat this latter group of patients. However, the published clinical studies have, to a large extent, excluded older patients: in the CONSENSUS study ${ }^{4}$ the mean age was 71 years, in the SOLVD study ${ }^{5}$ the mean age was 61 years (patients over 80 were excluded), in the $\mathrm{SAVE}^{9}$ study the mean age was 59 years and in the $\operatorname{AIRE}^{6}$ study the mean age was $65 \pm 11$ years. There is, of 
course, no reason to believe that elderly patients with heart failure are different from younger patients. Indeed, in the GISSI-3 trial, ${ }^{11}$ there was an even greater reduction in cardiovascular events in patients over 70 years, when compared to those under 70 years, who were treated with lisinopril following acute myocardial infarction.

Our results also suggest that coronary heart disease is the most frequently encountered cause of congestive heart failure in patients presenting to hospital. Furthermore, hypertension was found to be a predisposing risk factor in $25 \%$ of patients with heart failure. In the past, hypertension was the major contributor to the increased incidence of heart failure in the general population (preceding heart failure in approximately $75 \%$ of all cases). ${ }^{1}$ Although conclusive evidence is lacking, it has been postulated that the main reason to account for this change in the aetiology of heart failure, is the better management of severe hypertension over the last 30 years. Recent trials have also shown that treatment with warfarin significantly reduces the incidence of stroke among patients with atrial fibrillation (20-30 strokes prevented per 1000 patient years of treatment). As a result, there have been calls for the increased use of anticoagulant drugs in these patients. ${ }^{18-20}$ Even though our survey did not primarily examine the use of anticoagulation in patients with atrial fibrillation, it is clear that,

1 McKee PA, Castelli WP, McNamara PM, Kannel WB. The natural history of congestive heart failure: the Framingham Study. $N$ Engl $\mathcal{F}$ Med 1971; 285: 1441-6.

2 McMurray J Dargie HJ. Trends in hospitalisation for chronic heart failure in the United Kingdom. Eur Heart $\mathcal{f}$ chronic heart failure in

3 Sutton GC. Epidemiologic aspects of heart failure. $A m$ Heart $₹$ 1990; 120: 1538-40

4 CONSENSUS Trial Study Group. Effects of enalapril on mortality in severe congestive heart failure. Results of the co-operative north Scandinavian enalapril survival study. $N$ Engl f Med 1987; 316: 1429-35.

5 The SOLVD Investigators. Effect of enalapril on survival in patients with reduced left ventricular ejection fractions and

congestive heart failure. N Engl F Med 1991; 325: 293-302.

6 The Acute Infarction Ramipril Efficacy (AIRE) Study Investigators. Effect of ramipril on mortality and morbidity of survivors

7 The SAVE investigators. Effects of captopril on mortality and morbidity in patients with left ventricular dysfunction after myocardial infarction: results of the survival and ventricular enlargement trial. $N$ Engl f Med 1992; 327 669-77.

8 Ambrosioni E, Borghi C, Magnani B, for the Survival of Myocardial Infarction Long-term Evaluation (SMILE) study investigators. N Engl f Med 1995; 332: 80-5.

9 The SOLVD Investigators. Effect of enalapril on mortality and the development of heart failure in asymptomatic and the development of heart failure in asymptomatic patients with reduced left ventricul

10 Konstam MA, Kronenberg MW, Rousseau MF, et al. Effects of the angiotensin converting enzyme inhibito enalapril on the long-term progression of left ventricula dilatation in patients with asymptomatic systolic function Circulation 1993; 88: 2277-83.

11 Gruppo Italiano per lo Studio della Sopravvivenza nell'Infarto Micardio GISSI-3 effects of lisinopril and transdermal glyceryl trinitrate singly and together on 6-week mortality and ventricular function after acute myocardial infarction. Lancet 1994; 343: 1115-22. at least in those patients with heart failure and atrial fibrillation, warfarin has been prescribed in the majority of patients to reduce the risk of embolic stroke; all but one patient not receiving warfarin were over 75 years of age where the adverse effects of anticoagulants are increased. However, it is increasingly recognised that warfarin is safe in selected elderly patients, and indeed the elderly may' be the group that benefit most in terms of stroke prevention. $^{21}$

In conclusion, our results clearly demonstrate that in patients admitted to hospital with heart failure, one in four patients who should be receiving an ACE inhibitor by the time of discharge, are not. This is surprising in view of the overwhelming evidence that ACE inhibitors improve outcome in all patients with symptomatic or asymptomatic left ventricular dysfunction. Many of the patients who were prescribed an ACE inhibitor were given it at an inappropriate dose; only 24 patients $(16.7 \%)$ were on the dose that was used in the clinical trials where ACE inhibitors showed a reduction in mortality. The average age of the patients in our study was 76 years, ie, an older age group than most of published studies with ACE inhibitors. Specific studies looking at the effect of ACE inhibitors in elderly patients would be helpful, as well as studies to determine the optimum treatment regimen for this age group.

12 ISIS Collaborative Group. A randomised factorial trial assessing early oral captopril, oral mononitrate, and intravenous magnesium sulphate in 58,050 patients with intravenous magnesium sulphate in 58 , 050 patients with suspected

13 Ghali JK, Cooper R, Ford E. Trends in hospitalisation rates for heart failure in the United States, 1973-1986. Evidence for increasing population prevalence. Arch Intern Med 1990; 150: 769-73.

14 McMurray J, McDonagh T, Morrison CE, Dargie HJ. Trends in hospitalisation for heart failure in Scotland. Eur Heart $\mathcal{F}$ 1993; 14: 1158-62.

15 Clark AL, Coats AJS. Severity of heart failure and dosage of angiotensin converting enzyme inhibitors. BMF 1995; 310: $973-4$.

16 Dargie HJ, McMurray JV. Diagnosis and management of heart failure. $B M F$ 1994; 308: 321-8.

17 Kannel WB, Belanger BAJ. Epidemiology of heart failure. Am Heart f 1991; 121: 951-7.

18 Petersen P, Boysen G, Godtfredsen J, Andersen ED, Andersen B, for the Copenhagen AFASAK study. Placebocontrolled, randomised trial of warfarin and aspirin for prevention of thromboembolic complications in chronic atrial fibrillation. Lancet 1989; 1: 175-9.

19 Boston Area Anticoagulation Trial for Atrial Fibrillation Investigators. The effect of low-dose warfarin on the risk of stroke in patients with non-rheumatic atrial fibrillation. $N$ Engl f Med 1990; 323: 1505-11.

20 Bath PMW, Prasad A, Brown MM, MacGregor GA. Survey of use of anticoagulation in patients with atrial Survey of use of anticoagulation

21 Gurwitz JH, Goldberg RJ, Holden A, Knapic N, Ansell J. Age related risks of long term oral anticoagulation therapy. Arch Intern Med 1988; 148: 1733-6. 